\title{
Autolysis of Bacterial Cells Leads to Formation of Empty Sheaths by Leptothrix spp.
}

\author{
Tomoko Suzuki ${ }^{1}$, Hiromichi Ishihara ${ }^{1}$, Kazuhiro Toyoda ${ }^{2}$, Tomonori Shiraishi ${ }^{2}$, \\ Hitoshi Kunoh ${ }^{1}$ and Jun Takada ${ }^{1, *}$
}

1 Department of Material Chemistry, Graduate School of Natural Science and Technology, Okayama University, 3-1-1 Tsushima-naka, Kita-ku, Okayama 700-8530, Japan;

E-Mails: suzukito@cc.okayama-u.ac.jp (T.S.); hishihara@cc.okayama-u.ac.jp (H.I.); hkunoh@cc.okayama-u.ac.jp (H.K.)

2 Laboratory of Plant Pathology, Graduate School of Environmental Science, Okayama University, 1-1-1 Tsushima-naka, Kita-ku, Okayama 700-8530, Japan; E-Mails: pisatin@cc.okayama-u.ac.jp (K.T.); tomoshir@bio-ribs.com (T.S.)

* Author to whom correspondence should be addressed; E-Mail: jtakada@cc.okayama-u.ac.jp; Tel.: +81-86-251-8106; Fax: +81-86-251-8087.

Received: 3 April 2013; in revised form: 3 June 2013 / Accepted: 14 June 2013 /

Published: 20 June 2013

\begin{abstract}
The aquatic, Fe-oxidizing bacteria Leptothrix spp. produce uniquely shaped extracellular sheaths composed of organic bacterial polymers encrusted with inorganic elements from its aquatic environments. At the initial stage of sheath formation, bacterial cells were aligned in the sheath, but later most sheaths became empty. Here, we studied the mechanism of sheath hollowing by examining an isolate of Leptothrix sp. strain OUMS1 cultured in either artificial medium or natural groundwater. After 3 days in the medium, most sheaths at the initial stage surrounded a line of live cells, while some cells in the line were dead regardless of their position in a sheath. In sheaths where cells and/or their remnants were barely distinguishable by differential interference contrast microscopy (DIC), a vital stain and a stain specific for nucleic acids occasionally revealed dead cells and/or nucleic acid remnants, while sheaths that lacked a positive response to these reagents looked transparent when viewed with DIC. In specimens cultured in the medium for 7 days, dead cells increased in number regardless of their position in the sheath. Almost the same phenomena occurred in specimens cultured in natural groundwater until day 7 . Transmission electron microscopy (TEM) showed that cells degenerated, leading to
\end{abstract}


autolysis of bacterial cells in the sheath. These observations led us to conclude that autolysis of bacterial cells could be a major cause of sheath hollowing.

Keywords: empty sheath; Leptothrix spp; iron-oxidizing bacteria; autolysis; L/D and DAPI dual staining

\section{Introduction}

The genus Leptothrix, a type of Fe/Mn-oxidizing bacteria belonging to the aquatic $\beta$-proteobacteria [1-3], is characterized by its formation of an extracellular, tubular, Fe- or Mn-encrusted sheath, enabled by the Fe/Mn-oxidizing capacities of this genus [4-6]. The formation of a sheath that contains bacterial cells and extracellular metal-oxidizing activities are the two major phenotypic criteria that distinguish Leptothrix species from closely related bacteria [1,7]. Although the presence of a sheath is thought to confer nutritional and ecological advantages to species of Sphaerotilus and Leptothrix and enables the bacterial cells to attach themselves to solid surfaces and protects them against parasites and predators [1,3], sufficient evidence to explain the significance of the sheath in these bacteria is still lacking.

Recently, Takeda et al. [8] studied sheath elongation in L. cholodnii in detail using fluorescence and phase-contrast microscopy and discovered that the bacterial cells continuously elongated and divided regardless of their position in the sheath and that the sheath itself was open-ended and elongated at its terminal regions. This observation is consistent with the earlier description by Ghiorse [9] that sheath formation of $S$. natans and Leptothrix spp. takes place during elongation of bacterial cells at the ends of cell chains. Their results indicate that the bacterial cells maintain their ability to proliferate and continuously excrete polymers, which leads to the formation of the initial frame of sheath [3-5]. When isolated strains are cultured in artificial media, most sheaths contain bacterial cells at an early stage of incubation $[2,4,5,8]$. However, the majority of sheaths, especially those that are thick and yellow-brownish, become at least partially empty within a few days after the start of the incubation, resembling most of the sheaths of $L$. ochracea when harvested from natural aquatic environments [10,11]. According to Emerson et al. [12], when the sheaths are actively growing, only approximately $10 \%$ of the sheaths contain filaments of rod-shaped bacterial cells. Ghiorse noted in his review [9] that in low-nutrient, Fe-containing enrichment cultures, L. ochracea synthesized and vacated iron-encrusted sheaths very rapidly, leaving behind a large mass of empty sheaths. However, the manner in which the sheaths were vacated was not explained. Are the bacterial cells released one by one from the open ends of the sheaths? Or degraded by cell autolysis or some other process? Evidence to answer these queries still remains insufficient.

As illustrated in Figure 1A, almost all sheaths of L. ochracea harvested from the pilot groundwater tank at the farm of Okayama University had clear thick walls. Although most of these sheaths looked empty, a few chained bacterial cells were occasionally seen within some sheaths. Treatment of such sheaths with a protein-specific fluorescent dye, Ruby, a protein detector frequently used in molecular biology, clearly marked the location of active bacterial cells (Figure 1B, solid arrow) and occasional intercellular spaces running lengthwise within the sheaths. In addition, small fluorescent aggregates of 
various sizes were occasionally seen in these intercellular spaces (Figure 1B, dotted arrows). These observations led us to assume that such spaces and aggregates might be associated with the hollowing mechanism in the sheaths. To verify this assumption, we studied the behavior of cells of Leptothrix sp. strain OUMS1 (NITE BP-860) (hereafter referred to as OUMS1) cultivated in an artificial medium and in natural groundwater using light and electron microscopy.

Figure 1. Sheaths produced by Leptothrix ochracea harvested from natural aquatic environment. (A) Thick, yellowish-brown, empty sheaths and (B) entire bacterial cell (solid arrow) and proteinic remnants (dotted arrows) within a sheath detected by protein-specific reagent, Ruby. Scale bar $=10 \mu \mathrm{m}$.

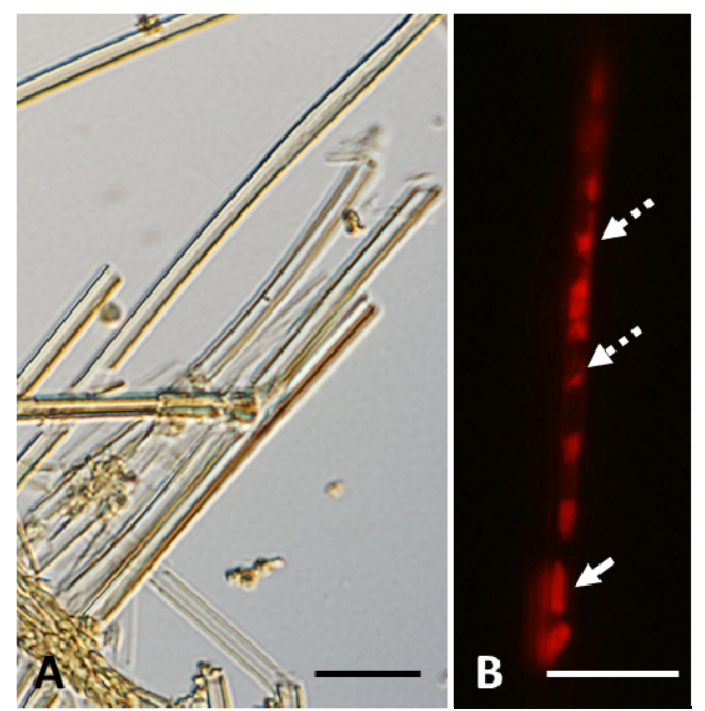

\section{Results and Discussion}

When OUMS1 was cultured in silicon-glucose-peptone broth (SGP broth [13]) with a small iron plate (hereafter referred to as SGPI broth) for 3 days, a great number of the initial sheaths surrounding chained cells were seen in addition to abundant free or aggregated cells, as reported previously [6]. The adjacent, aligned cells (Figure 2A, solid arrow) in the initial sheath comprised a faint, thin film but were not always tightly connected, and thus intercellular spaces were often observed with DIC microscopy (Figure 2A, dotted arrow). Most of the cells enclosed in sheaths proved to be alive by fluorescing green after the bacterial viability kit staining (LIVE/DEAD ${ }^{\circledR}$ Bac Light $^{\mathrm{TM}}$, L7007, Molecular Probes, Eugene, OR, USA) (hereafter referred to as L/D staining) [4] (Figure 2B). The characteristic blue fluorescence of 4',6-diamidino-2-phenylindole dihydrochloride $n$-hydrate (DAPI, WAKO Chemicals, Osaka, Japan) [4] showed nucleic acids in the chained cells (Figure 2C). Probably because of its intensity, the blue fluorescence seemed to be emitted from the entirety of each cell, and the precise location of nucleic acids within the cells could not be determined. Although the body marked by a solid arrow in Figure 2A looks like one independent long cell with DIC imagery, the L/D and DAPI double-stained image (Figure 2B,C) revealed a slight constriction at a center of the body, and the fluorescing nucleic acid regions were "split" on each side of the constriction. Such images may represent mid-stream cell division as described by Takeda et al. [2], indicating that cell division and sheath elongation take place successively in the medium. Van Veen et al. [3] noted in their review that 
the cells of $L$. ochracea moved out of the sheaths at a rate of 1 to $2 \mu \mathrm{m} / \mathrm{min}$, and subsequently produce new sheaths, suggesting that the formation of empty sheaths might ascribe to cellular motility. If the cell division occurs always at the end of sheath, the release of cells from open ends of sheath may be persuasive. However, the present observations (Figure 2B,C) showing the continuous occurrence of cell division at the central part of sheaths raised a question how these cells move out of the sheaths. Although most sheaths contained single and chained live cells, sheaths having fully shaped cells and lengthwise empty-looking intercellular spaces were found intermittently. In the DIC image Figure 2D, solid and dotted arrows indicate bacterial cells and empty-looking spaces, respectively. In the same view area, L/D detected live cells with greenish fluorescence (Figure 2E, solid arrows) and dead cells with reddish fluorescence (Figure 2E, dotted arrow). DAPI detected fluorescent nucleic acid in the live cells (Figure 2F, solid arrows) and atypical pinkish fluorescence from dead cells with damaged membranes (Figure 2F, dotted arrows). These observations warned us not to judge the emptiness of sheaths only by DIC imaging.

It is noteworthy that the sheaths in Figure 2D were coated with fibrous materials (Figure 2D, fm). Furutani et al. [4] reported that cultivation of OUMS1 in silicon-iron-glucose-peptone (SIGP) medium [6] with three iron plates led to the formation of sheaths with extremely thick walls, with an outer coat covered with thin, loosely woven fibrils and thick assembled fibrils. Suzuki et al. [14] observed that when OUMS1 was cultured in natural groundwater by the dialysis tube method, the sheath wall became much thinner; thus artificial cultivation was considered to promote the excretion of polymers from the cells, resulting in wall thickening. The fibrous materials on the sheath surfaces in Figure 2D most likely correspond to the fibrous assembly of extracellular polymers from the bacterial cells, as Furutani et al. [4] reported.

As illustrated in Figure 2G-I, the continuous cultivation of OUMS1 until day 7 resulted in more sheaths with dead cells. Most sheaths had sharply defined walls coated with fibrous materials (Figure 2G). Bacterial cells were barely distinguishable in the sheaths when viewed with DIC (Figure 2G, solid arrows) and were interspersed with granular zones (Figure 2G, dotted arrows) in the intercellular spaces. These barely distinguishable cells fluoresced when stained with L/D or DAPI, showing them to be live cells with nucleic acids (Figure 2H,I). By contrast, dead cells were detected in the indistinct, granular, intercellular zones (Figure 2G, dotted arrows) (Figure 2H,I). There was no regularity in the appearance of dead cells in the cell chains, but fewer cells tended to die at the ends of the sheath. The clearly delineated sheath zone (marked with an arrowhead in Figure 2G) never responded to L/D or DAPI (Figure 2H,I), suggesting that the bacterial cells and their remnants completely degenerated there to leave an empty sheath. All these observations led us to consider that formation of empty sheaths was at least partially due to autolysis of the bacterial cells in addition to cell release from the sheath ends as suggested by van Veen [3]. However, we cannot rule out the possibility that such autolysis could be caused by artificial cultivation. 
Figure 2. Strain OUMS1 and associated structures cultured in SGPI broth for $3(\mathbf{A}-\mathbf{F})$ and 7 days $(\mathbf{G}-\mathbf{I})$; DIC images $(\mathbf{A}, \mathbf{D}, \mathbf{G})$ and fluorescent images from L/D stain $(\mathbf{B}, \mathbf{E}, \mathbf{H})$ and from DAPI stain $(\mathbf{C}, \mathbf{F}, \mathbf{I})$; images within a column are of the same cells. (A-C) Line of bacterial cells (solid arrow) and lengthwise intercellular spaces (dotted arrow) are encompassed by a faint, thin sheath. The cells (solid arrow) fluoresced a typical green from the L/D stain (vital sign), their nucleic acids fluoresced blue from DAPI, but the intercellular spaces (dotted arrow) did not fluoresce. Note the constriction at the center of the bacterial body [solid arrow in (B) and (C)], signifying active cell division. (D-F) DIC-fluorescing cells (solid arrows) and barely fluorescing cells (dotted arrows) are enclosed with clearly defined walls covered with fibrous materials (fm). L/D and DAPI detected live cells (solid arrows) with intact nucleic acids and dead cells (dotted arrow) with atypical nucleic acids fluorescing pinkish. And (G-I) Barely distinguishable cells (solid arrows) enclosed with a thick-walled sheath, empty-looking (dotted arrows) and transparent zones with no detectable cells or cell remnants (arrowhead) in (G). Solid arrows: live cells with intact nucleic acid response; dotted arrows: dead cells with degenerated nucleic acids. Scale bar $=5 \mu \mathrm{m}$.
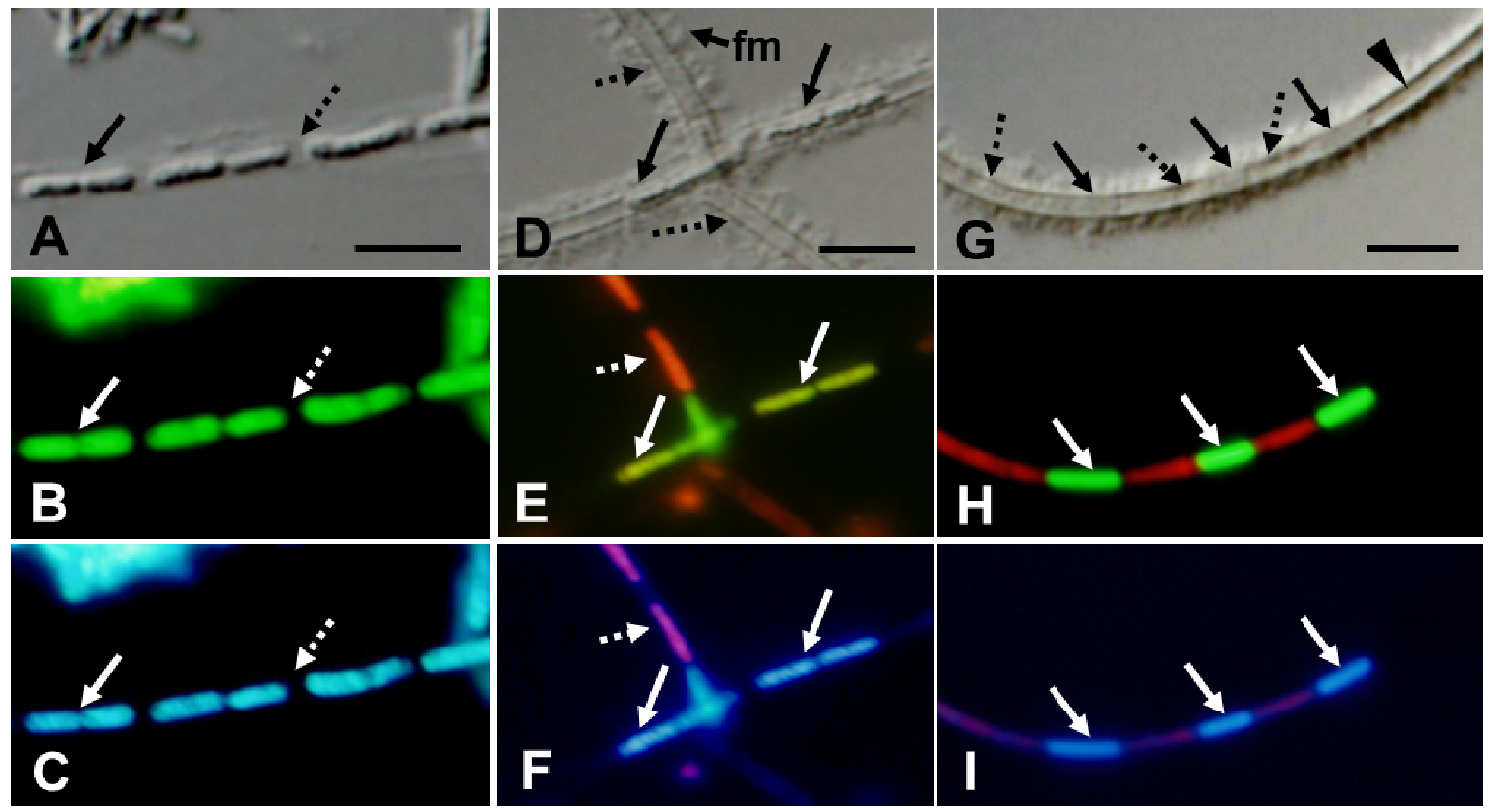

To verify this possibility, OUMS1 was cultivated in natural groundwater using the dialysis tube method [14]. As illustrated in Figure 3A, a line of fully shaped bacterial cells (solid arrows) and small aggregates (dotted arrow) were occasionally seen in a clearly delineated sheath after 3 days in groundwater. As expected, the fully shaped cells showed positive L/D and DAPI responses (Figure 3B,C, arrows), while the small aggregates did not fluoresce from L/D (Figure 3B, dotted arrow) and gave only a slightly blue DAPI response (Figure 3C, dotted arrow), suggesting that the nucleic acids had probably degenerated. After 7 days, more dead cells appeared in sheaths (Figure 3D-F, dotted arrow). Again, in cells that looked fully shaped in the DIC image (Figure 3D, solid arrows) actually had a slight constriction in the center of the body in the L/D and DAPI images (Figure 3E,F, solid arrows). These observations demonstrated that bacterial cells were successively dividing within the sheath and that a number of cells had autolysed within the same sheath, regardless of their position, 
similar to cultivation in broth. In groundwater cultivation, abundant particle assemblies always gathered at discrete locations along the sheaths (Figure 3A,D, ap). Van Veen et al. [3] reported a similar phenomenon when L. cholodnii was grown in the presence of $\mathrm{Mn}^{2+}$; the sheaths became irregularly covered with granular manganese oxide. In a separate SEM-EDX observation, these particles were shown to contain $\mathrm{Fe}, \mathrm{O}, \mathrm{P}$ and $\mathrm{Si}$ as major elements, suggesting that they could aggregate via autooxidation of aquatic-phase elements and/or unidentified chemical bonds (Appendix Figure A1).

Figure 3. OUMS1 and associated structures cultivated in groundwater for $3(\mathbf{A}-\mathbf{C})$ and 7 days $(\mathbf{D}-\mathbf{F})$. DIC images $(\mathbf{A}, \mathbf{D})$ and L/D- $(\mathbf{B}, \mathbf{E})$ and DAPI- $(\mathbf{C}, \mathbf{F})$ fluorescent images. (A-C) Line of cells (solid arrows) and cell remnants (dotted arrow) enclosed in a thick-walled sheath. Fully shaped cells (solid arrows) with a live response and sign of nucleic acids and cell remnants (dotted arrow) lacking a vital response and nucleic acids. Assembled particles (ap) are seen at discrete locations along the sheaths. And (D-F) fully shaped live cells with fluorescing nucleic acids (solid arrows) and deformed, and dead cells with damaged DNA (dotted arrow) in a thick-walled sheath. Scale bar $=5 \mu \mathrm{m}$.

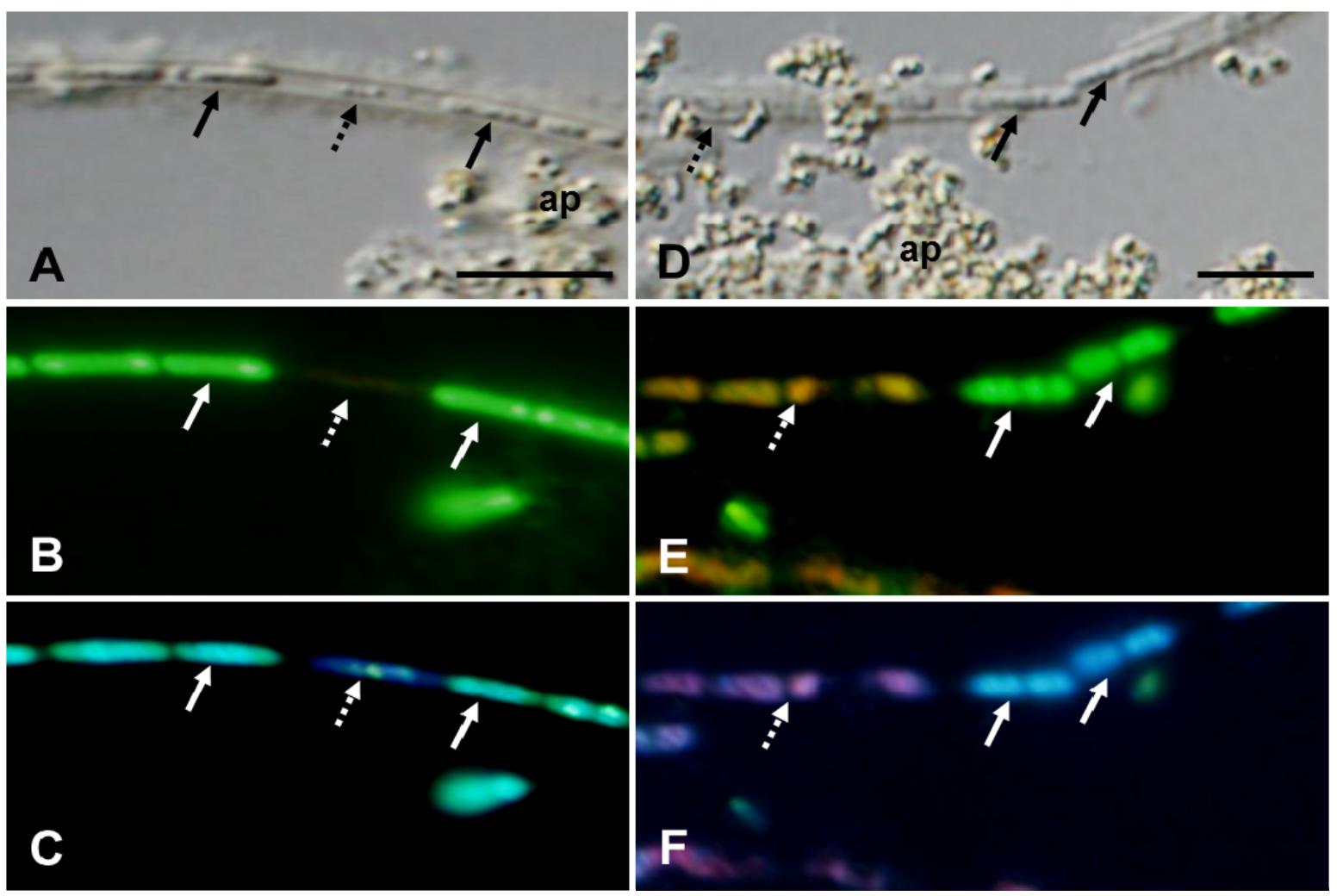

When specimens cultured in SGPI broth for 3 days were observed with TEM, some sheaths, characterized by a thin or electron-dense thick wall, enclosed bacterial cells (Figure 4A, arrows), while other sheaths contained degenerated and deformed cell remnants (Figure 4A, dotted arrows), as reported for cultured L. discophora SP-6 by Emerson and Ghiorse [7]. As illustrated in a longitudinal section of a sheath (Figure 4B), a body that maintained the shape of a cell (arrow) occasionally coexisted side-by-side with cell remnants (dotted arrow) within a sheath. The extremely electron-dense fibrous assembly in the sheath zone corresponds to saccharic bacterial fibrils incorporated with aquatic inorganic elements [5]. 
Figure 4. Transmission electron micrographs of cross (A) and longitudinal sections (B) of sheaths harvested on day 3 of culture in SGPI broth. (A) Some sheaths enclosed fully shaped cells (bc), but others contained deformed cells or their remnants (dotted arrows). And (B) thick, electron-dense sheath walls enclose a fully shaped cell and cell remnants (dotted arrow) side by side. Scale bar $=1 \mu \mathrm{m}$.

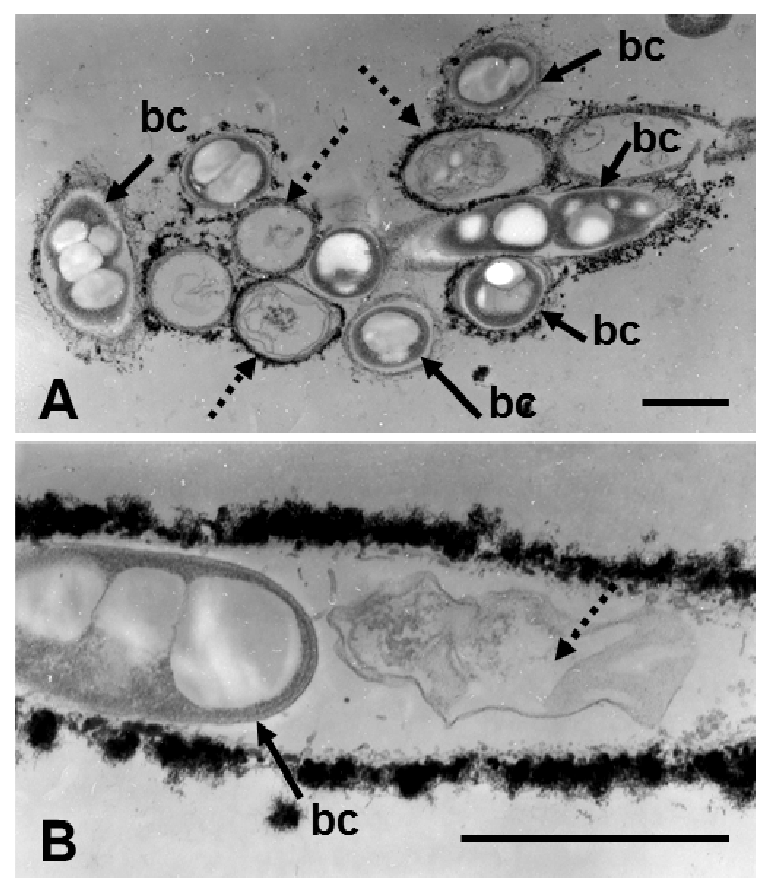

In a similar TEM study of specimens cultivated in groundwater for 3 and 7 days, some of the 3-day sheaths were comprised of a fibrous assembly, and cells were in a line but separated by the intercellular spaces (Figure 5A). As Takeda et al. [8] reported, at the end of the initial sheath comprised of fine fibrils, two cells were occasionally seen to be connected by a thin constriction (Figure 5B, arrow), most likely reflecting the phase right before completion of cell division. Such a cell may readily move out of the end of sheaths, as noted by van Veen [3]. In most of the 7-day sheaths, aligned cells were separated by broader intercellular spaces, and their cytoplasm was electron-lucent, suggesting initiation of autolysis (Figure 5C). Some cells in the sheaths had lost organelles, and the cytoplasm had become granular, signs of autolysis (Figure 5D). The presence of intercellular spaces likely reflects that free, independent cells could move after cell division within fluid-phased sheaths. Although OUMS1 cells have been reported to have a monotrichous, polar flagellum [4], it is unknown whether the movement of cells is due to active flagellar locomotion and/or passive fluid flow within the sheaths. The possibility remains that such solo travel of free cells within sheaths may trigger their early autolysis after cell division, because it is generally accepted that formation of a biofilm on solid surfaces and/or colony through the attachment of cells are essential for survival $[3,15]$.

All these observations demonstrated that (i) bacterial cells maintain the ability to proliferate within sheaths; (ii) cells separate from adjacent cells soon after cell division; (iii) cells seem to autolyse probably within a short time after cell division (the precise time is unknown at present, because the life span of bacterial cells is largely influenced by the species, environmental and nutritional factors as noted by Madigan et al. [15]); and (iv) their autolysis leads to a hollowing of the Leptothrix sheaths. Since the presence of the phage-related intergrases and DNA polymerase-related components is shown 
in genomic DNA of L. cholodnii SP-6 (DNA Data Bank of Japan), possible involvement of the template phage in autolysis of the cells can not be ruled out. Based on the present microscopic observation and the literature information, we are continuing to elucidate why and when the cells autolyse within the sheaths.

Figure 5. Transmission electron micrographs of sheaths harvested at day $3(\mathbf{A , B})$ and $7(\mathbf{C}, \mathbf{D})$ of culture in groundwater. (A) Cells (bc) aligned in a sheath (s) composed of fibrous materials. Note that adjacent cells in the sheath are separated by intercellular spaces (is). (B) Two dividing cells connected to each other by a thin connection (arrow). The sheath comprises an assembly of thin fibrils, suggesting that this part of sheath could be the terminal end. (C) Cells separated by broad intercellular spaces in a sheath harvested from 7-day culture. Their cytoplasm has begun to degenerate. And (D) Cell with granular cytoplasm (a sign of degeneration). (A-C) Scale bar $=1 \mu \mathrm{m}$; (D) Scale bar $=500 \mathrm{~nm}$.

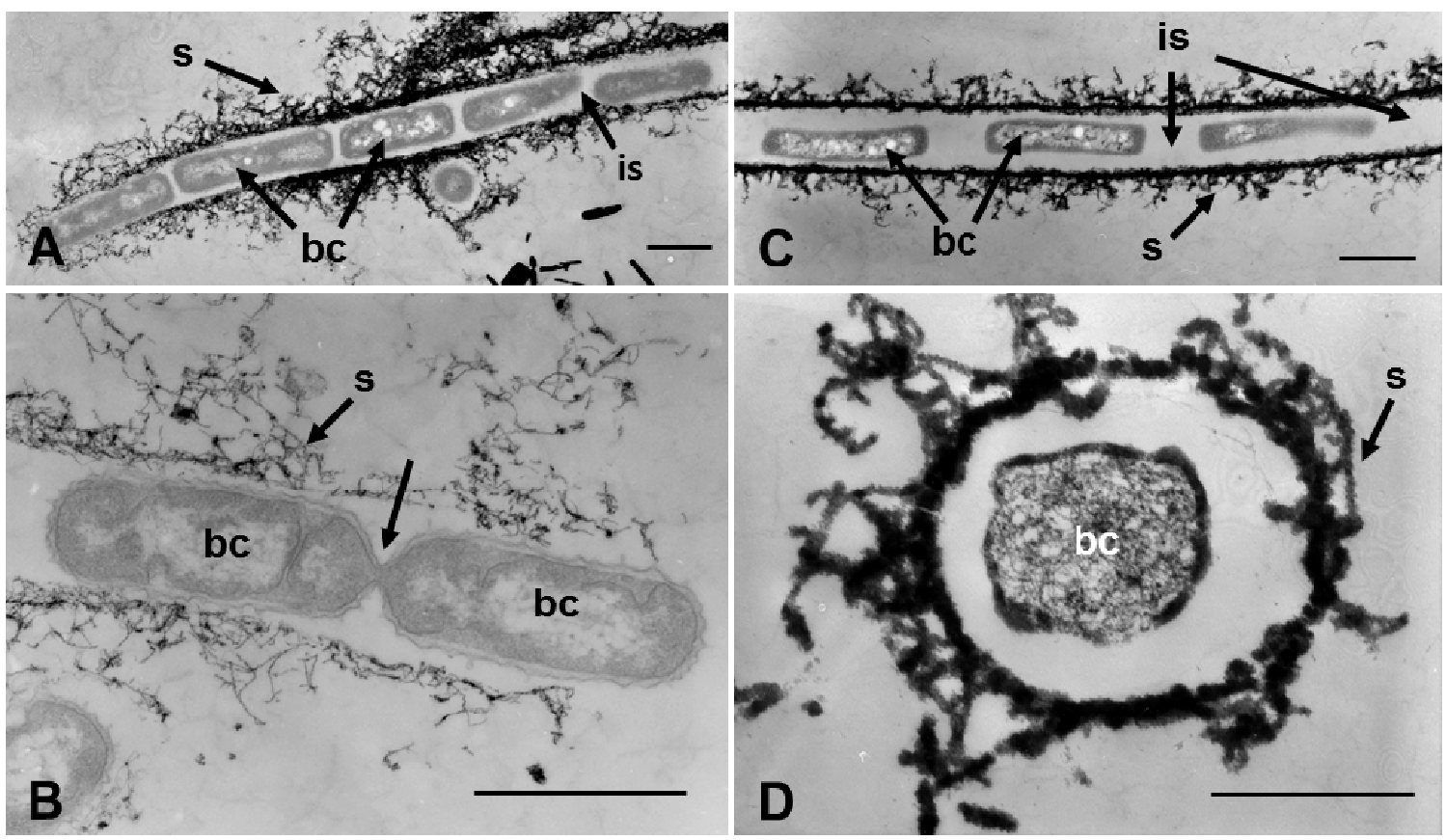

\section{Experimental Section}

\subsection{Sample and Culturing}

OUMS1 recovered from the frozen stock culture was grown in SGPI broth on a rotary shaker at $20{ }^{\circ} \mathrm{C}$ and $70 \mathrm{rpm}$ for 3 and 7 days and was subjected to microscopy. Alternatively, to grow OUMS1 in the natural aquatic condition, we used a unique dialysis tube method devised by Suzuki et al. [14] as follows. Briefly, OUMS1 was preliminarily incubated in a SGP broth [13] on a rotary shaker at $20{ }^{\circ} \mathrm{C}$ and $70 \mathrm{rpm}$ for 2 days, then collected by centrifugation at $4000 \times \mathrm{g}$ for $10 \mathrm{~min}$. The suspended bacterial cells and associated sheaths were vortexed in sterilized distilled water. Ten milliliters of the vortexed sample was transferred into a $50 \mathrm{~mL}$ tube through a 23 -gauge needle on a $10-\mathrm{mL}$ syringe to disrupt aggregates, followed by filtration with a membrane filter $(1.2 \mu \mathrm{m}$ pore diameter, Merck Millipore Co., Billerica, MA, USA) to remove sheaths and debris. After confirming by light microscopy that the filtrate contained only bacterial cells but not sheaths, the filtrate was used as the final bacterial suspension. A cellulose 
dialysis tube (19 mm width, Japan Medical Sci., Takasaki, Japan) was cut into pieces of $15 \mathrm{~cm}$ each, followed by repeated boiling in distilled water and autoclaving. One end of the tube piece was folded and pinched with a clamp to create a small, airless bag, and $5 \mathrm{~mL}$ of the final bacterial suspension was injected into the bag. Similarly, the other end of the tube was folded and clamped to create a bag ca. $4 \mathrm{~cm}$ long. The bags were then immersed in a container located at the farm of Okayama University through which natural groundwater was continuously flowing. A few bags were removed from the container at days 3 and 7 of culture to examine the specimens. The samples were repeatedly washed with distilled water and prepared for microscopy.

\subsection{Light Microscopy}

The collected samples were washed repeatedly with sterilized ultrapure water by centrifugation and subjected to the following specific staining and DIC and fluorescent microscopy.

The specimens were double-stained with L/D and DAPI. The sample suspension $(200 \mu \mathrm{L})$ in Eppendorf tubes was centrifuged at $2300 \times \mathrm{g}$ for $3 \mathrm{~min}$. The specimen was resuspended in an Eppendorf tube with $0.85 \% \mathrm{NaCl}$ and stained with the bacterial viability kit using the manufacturer's protocol. Twenty microliters of the specimen suspension was mixed with $6 \mu \mathrm{L}$ of 100 times-diluted component A $\left(300 \mu \mathrm{L}\right.$ of a mixture of $1.67 \mathrm{mM} \mathrm{SYTO}^{\circledR} 9$ dye and $1.67 \mathrm{mM}$ propidium iodide in DMSO) and incubated at room temperature in the dark for $15 \mathrm{~min}$. After addition of $9 \mu \mathrm{L}$ of $50 \mu \mathrm{g} / \mathrm{mL}$ DAPI solution, the suspension was incubated in the dark at room temperature for $5 \mathrm{~min}$. A small drop of the stained specimen was observed with fluorescence microscopy (BX51, Olympus, Tokyo, Japan) using a U-MWIB3 dichroic mirror unit for L/D staining (460-490 nm excitation filter and $520 \mathrm{~nm}$ emission wavelength) and U-MWU2 dichroic mirror unit for DAPI (330-360 nm excitation filter and $430 \mathrm{~nm}$ emission wavelength). With this double stain and filter condition for fluorescence microscopy of $\mathrm{L} / \mathrm{D}$, live bacteria with intact cell membranes stained fluorescent green, whereas those with damaged membranes stained fluorescent orange to red [4]. For DAPI, nucleic acids in live cells give off a bluish fluorescence, while those in dead cells with damaged membranes fluoresce pink to red [16]. Such fluorescence is due to combined blue fluorescence of DAPI and red fluorescence from propidium iodide (one of the components of the L/D reagent) [16].

\subsection{Electron Microscopy}

Specimens were collected by centrifugation and fixed with a mixture of $2.5 \%$ glutaraldehyde, $1 \% \mathrm{OsO}_{4}$, and $4.5 \%$ sucrose in $100 \mathrm{mM}$ cacodylate buffer $(\mathrm{pH} 7.0)$ on ice for $2 \mathrm{~h}$ and then embedded in 2\% agar. Small pieces of the washed agar block were dehydrated in a graded series of ethanol and again embedded in Quetol 651 resin mixture (Nisshin EM, Tokyo, Japan). Ultrathin sections were stained with uranyl acetate and lead solution, then observed with TEM (H-7500, Hitachi, Tokyo, Japan) at an accelerating voltage of $80 \mathrm{kV}$.

\section{Conclusions}

An isolated strain of Leptothrix sp. OUMS1 was cultured in either artificial medium or natural groundwater to examine the mechanism of sheath hollowing. DIC, a vital stain and a stain specific for 
nucleic acids revealed that after 3 days in the medium, most sheaths at the initial stage surrounded a line of live cells, while some cells in the line were dead regardless of their position in a sheath. In sheaths where cells and/or their remnants were barely distinguishable by DIC, the stains occasionally revealed dead cells and/or nucleic acid remnants, while sheaths that lacked a positive response to these reagents looked transparent when viewed with DIC. After 7 days in the medium, dead cells increased in number regardless of their position in the sheath. Almost the same phenomena occurred in natural groundwater until day 7. Transmission electron microscopy showed that cells degenerated, leading to autolysis of bacterial cells in the sheath. These observations led us to conclude that autolysis of bacterial cells could be one of the causes of sheath hollowing.

\section{Acknowledgments}

This study was financially supported by the Special Grant for Education and Research (2008-2013) from the Ministry of Education, Culture, Sports, Science, and Technology, Japan (J.T.), JSPS KAKENHI Grant Number 24780073 (T.S.) and by JST, CREST (2012-2016) (J.T.). We thank H. Yoshioka, Nagoya University, for his technical advice on the use of Ruby. We acknowledge B.E. Hazen, Cortland, NY, USA for reviewing and editing the manuscript before submission.

\section{Conflict of Interest}

The authors declare no conflict of interest.

\section{References}

1. Spring, S. The genera Leptothrix and Sphaerotilus. In The Prokaryotes, 3rd ed.; Dworkin, M., Falkow, S., Rosenberg, E., Schleifer, K.-H., Slackebrandt, E., Eds.; Springer Science: New York, NY, USA, 2006; Volume 5, pp. 758-777.

2. Takeda, M.; Makita, H.; Ohno, K.; Nakahara, Y.; Koizumi, J. Structural analysis of the sheath of a sheathed bacterium, Leptothrix cholodnii. Int. J. Biol. Macromol. 2005, 37, 92-98.

3. Van Veen, W.L.; Mulder, E.G.; Deinema, M.H. The Sphaerotilus-Leptothrix group of bacteria. Microbiol. Rev. 1978, 42, 329-356.

4. Furutani, M.; Suzuki, T.; Ishihara, H.; Hashimoto, H.; Kunoh, H.; Takada, J. Assemblage of bacterial saccharic microfibrils in sheath skeleton formed by cultured Leptothrix sp. strain OUMS1. J. Mar. Sci. Res. Dev. 2011, S5, doi:10.4172/2155-9910.S5-001.

5. Furutani, M.; Suzuki, T.; Ishihara, H.; Hashimoto, H.; Kunoh, H.; Takada, J. Initial assemblage of bacterial saccharic fibrils and element deposition to form an immature sheath in cultured Leptothrix sp. strain OUMS1. Minerals 2011, 1, 157-166.

6. Sawayama, M.; Suzuki, T.; Hashimoto, H.; Kasai, T.; Furutani, M.; Miyata, N.; Kunoh, H.; Takada, J. Isolation of a Leptothrix strain, OUMS1, from ocherous deposits in groundwater. Curr. Microbiol. 2011, 63, 173-180.

7. Emerson, D.; Ghiorse, W.C. Ultrastructure and chemical composition of the sheath of Leptothrix discophora SP-6. J. Bacteriol. 1993, 175, 7808-7818. 
8. Takeda, M.; Kawasaki, Y.; Umezawa, T.; Shimura, S.; Hasegawa, M.; Koizumi, J. Patterns of sheath elongation, cell proliferation, and manganese (II) oxidation in Leptothrix cholodnii. Arch. Microbiol. 2012, 194, 667-673.

9. Ghiorse, W.C. Biology of iron- and manganese-depositing bacteria. Annu. Rev. Microbiol. 1984, $38,515-550$.

10. Emerson, D.; Revsbech, N.P. Investigation of an iron-oxidizing microbial mat community located near Aarthus, Denmark: Field studies. Appl. Environ. Microbiol. 1994, 60, 4022-4031.

11. Suzuki, T.; Hashimoto, H.; Ishihara, H.; Kasai, T.; Kunoh, H.; Takada, J. Structural and spatial associations between $\mathrm{Fe}, \mathrm{O}$, and $\mathrm{C}$ in the network structure of the Leptothrix ochracea sheath surface. Appl. Environ. Microbiol. 2011, 77, 7873-7875.

12. Emerson, D.; Flemming, E.J.; McBeth, J.M. Iron-oxidizing bacteria: An environmental and genomic perspective. Annu. Rev. Microbiol. 2010, 64, 561-583.

13. Ishihara, H.; Suzuki, T.; Hashimoto, H.; Kunoh, H.; Takada, J. Initial parallel arrangement of extracellular fibrils holds a key for sheath frame construction by Leptothrix sp. strain OUMS1. Minerals 2013, 3, 73-81.

14. Suzuki, T.; Ishihara, H.; Furutani, M.; Shiraishi, T.; Kunoh, H.; Takada, J. A novel method for culturing of Leptothrix sp. strain OUMS1 in natural conditions. Minerals 2012, 2, 118-128.

15. Madigan, M.T.M.; Martinko, J.M.; Dunlap, P.V.; Clark, D.P. Microbial ecosystem. In Brock Biology of Microorganisms, 12th ed.; Berriman, L., Carlson, G., Eds.; Pearson Benjamin Cummings: San Francisco, CA, USA, 2009; pp. 673-693.

16. Staats, M.; van Baarlen, P.; Schoutens, A.; van Kan, J.A.L. Functional analysis of NLP genes from Botrytis elliptica. Mol. Plant Pathol. 2007, 8, 209-214.

\section{Appendix}

Figure A1. SEM-EDX analysis of particles assembling at discrete sites along the OUMS1 sheaths harvested after 7 days of culture in natural groundwater. (A) SEM image; (B-E) Distribution maps of $\mathrm{O}, \mathrm{Fe}, \mathrm{Si}$, and $\mathrm{P}$, respectively.

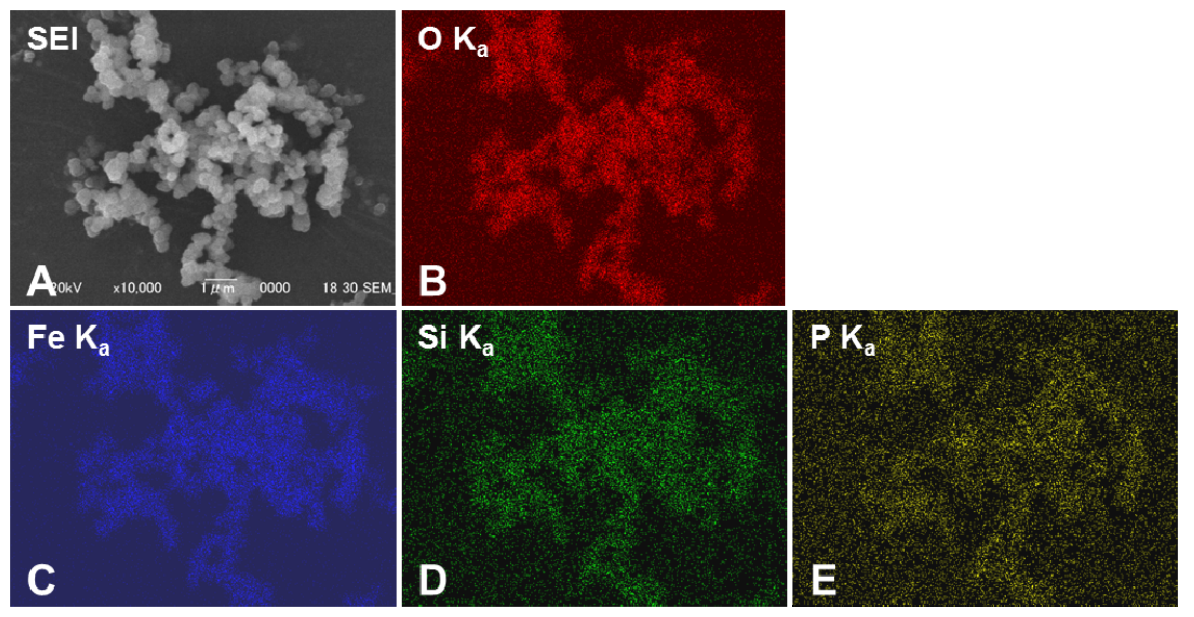

(C) 2013 by the authors; licensee MDPI, Basel, Switzerland. This article is an open access article distributed under the terms and conditions of the Creative Commons Attribution license (http://creativecommons.org/licenses/by/3.0/). 